\title{
Galloflavin Plus Metformin Treatment Impairs Pancreatic Cancer Cells
}

\author{
EDGAR HEINZ UWE WENDT, MARIA SCHOENROGGE, BRIGITTE VOLLMAR and DIETMAR ZECHNER
}

Institute for Experimental Surgery, Rostock University Medical Center, Rostock, Germany

\begin{abstract}
Background/Aim: In this study, we evaluated the effect of galloflavin, an inhibitor of lactate dehydrogenase, in combination with metformin, an anti-diabetic drug and inhibitor of oxidative phosphorylation, on pancreatic ductal adenocarcinoma cells. Materials and Methods: We explored the effect of galloflavin and metformin on proliferation and cell death of murine 6606PDA and human MIA PaCa-2 cells. Results: We observed that monotherapies of galloflavin and metformin both inhibit proliferation and induce cancer cell death. Moreover, the combination of both agents increased these effects on pancreatic ductal adenocarcinoma cells. The inhibition of proliferation by this combination therapy can be detected under hypoxic and normoxic conditions, leading to the assumption that this therapy might impair insufficiently supplied solid tumors as well as small clusters of cancer cells, e.g. after metastatic dissemination. Conclusion: Galloflavin, especially in combination with metformin, has a strong anti-cancerous effect on pancreatic ductal adenocarcinoma cells.
\end{abstract}

Pancreatic cancer patients have a very poor five-year relative survival of $9 \%$ for all stages (1). Hence, pancreatic cancer is the fourth leading cause of cancer-related death in both women and men in the USA. This demonstrates that surgical intervention plus adjuvant chemotherapy still lacks the needed efficacy to treat most of these patients successfully. Recent studies state that long-term ingestion of metformin, an often used anti-diabetic drug, is likely to reduce the risk of diabetic patients for the development of pancreatic cancer $(2,3)$. It was also suggested that metformin improves the survival of patients, who suffer from pancreatic cancer (4-

Correspondence to: PD Dr. rer. nat. Dietmar Zechner, Institute for Experimental Surgery, Rostock University Medical Center, Schillingallee 69a, 18057 Rostock, Germany. Tel: +49 381494 2512, Fax: +493814942502, e-mail: dietmar.zechner@unirostock.de

Key Words: Pancreatic ductal adenocarcinoma, cancer metabolism, combination therapy, polytherapy, anti-diabetic medication.
6). However, Wei et al. published a meta-analysis stating that mainly studies, which might be flawed by not considering the so-called immortal time bias, show an effect of metformin on pancreatic cancer (7). Moreover, Kordes et al. demonstrated that therapy with a regularly low anti-diabetic dose of metformin, besides standard chemotherapy, does not improve the overall survival compared to standard chemotherapy alone (8). However, this publication also suggested that patients with high metformin concentration in the blood might survive longer $(8,9)$. Thus, it is still controversially discussed, if this drug has an anti-cancerous effect and if metformin should be applied in combination with standard therapies or needs to be tested in combination with other experimental drugs. The anti-cancerous effect of metformin has been suggested to be mediated by its inhibition of oxidative phosphorylation (9), which is a key process to generate ATP. Another promising option for an effective chemotherapy is the inhibition of lactate dehydrogenase A (LDH-A) (10), which is a key enzyme in cancer, because cancer cells often favor metabolism via glycolysis (11-13). Indeed, genetic disruption of lactate dehydrogenases ablates the Warburg effect and restricts tumor growth (14). Thus, we decided to use galloflavin, an inhibitor of $\mathrm{LDH}$, to evaluate if it inhibits proliferation and can induce death in pancreatic cancer cells. We also tested the combination therapy, galloflavin plus a high dose of metformin, in order to gain a therapeutic benefit by impairing oxidative phosphorylation and glycolysis.

\section{Materials and Methods}

Reagents. Dimethyl sulfoxide (DMSO, code: D2438, SigmaAldrich, Darmstadt, Germany), phosphate buffered saline pH 7.4 (PBS, code: 10010-015, Thermo Fisher Scientific, Waltham, MA, USA), galloflavin (code: 4795, Tocris, Wiesbaden-Nordenstadt, Germany), metformin (code: D150959, Sigma-Aldrich), trypan blue (code: 15250, Thermo Fisher Scientific).

Cell culture and treatments. The murine pancreatic adenocarcinoma cell line 6606PDA, a gift from Prof. Tuveson (University of Cambridge, UK), and the human pancreatic cancer cell line MIA $\mathrm{PaCa}-2$, which was purchased from ATCC (Manassas, VA, USA), 
were cultured in Dulbecco's Modified Eagle's Medium (DMEM, code: FG0435, Biochrom GmbH, Berlin, Germany) containing 4,5 g/l glucose (high glucose) or in DMEM (Biochrom $\mathrm{GmbH}$ ) supplemented with glucose to a concentration of $0.5 \mathrm{~g} / \mathrm{l}$ (low glucose). The media were supplemented with $10 \%$ fetal calf serum (FCS, code S0615, Biochrom $\mathrm{GmbH}), 100$ units/ml penicillin and streptomycin (code A2212, Biochrom GmbH) and $8 \mu \mathrm{g} / \mathrm{ml}$ Tylosin (code: T3397, Sigma-Aldrich). The cells were treated with vehicle (DMSO), $5 \mu \mathrm{M}$, $20 \mu \mathrm{M}, 80 \mu \mathrm{M}$ and $320 \mu \mathrm{M}$ of galloflavin or each dosage combined with $20 \mathrm{mM}$ of metformin. In order to evaluate the influence of oxygen supply on drug efficacy, 6606PDA cells were cultured with the above drugs for $30 \mathrm{~h}$ under normoxic (19\% oxygen) or hypoxic (1\% oxygen) conditions in an Innova ${ }^{\circledR} \mathrm{CO}-48-230$ incubator (New Brunswick Scientific Co., Inc., Edison, NJ, USA).

Evaluation of lactate concentration, proliferation and cell death. Lactate was quantified in the cell lysate and supernatant by the lactate colorimetric assay kit II (BioVision Incorporated, Milpitas, CA, USA) after treating the cells with $80 \mu \mathrm{M}$ galloflavin or vehicle (DMSO) for $30 \mathrm{~h}\left(4 \times 10^{3}\right.$ cells per well were plated in a 96-well plate). Since high FCS concentrations interfered with the lactate assay, the cells were grown in medium only supplemented with $1 \%$ instead of $10 \%$ FCS.

For assessing proliferation, a kit (code: 11647229 001, Roche, Basel, Switzerland), which measured 5-bromo-2'-deoxyuridin (BrdU) incorporation into cells was used. After plating $8 \times 10^{3}$ 6606PDA or $4 \times 10^{3}$ MIA PaCa- 2 cells per well in a 96 -well plate, the cells were treated the next day with the indicated drugs for $24 \mathrm{~h}$. The BrdU assay was then performed as suggested by the manufacturer and the absolute absorption at $450 \mathrm{~nm}$ was determined using a PerkinElmer Victor X3 plate reader (PerkinElmer Inc., Waltham, MA, USA).

Cell death was quantified by trypan blue staining of cells. This dye stains cells, which are necrotic or in a late stage of apoptosis. In order to quantify dead cells, $3 \times 10^{4} 6606 \mathrm{PDA}$ or $2.5 \times 10^{4}$ of MIA PaCa- 2 cells per well were plated in a 24 -well plate. On the following days the cells were treated for $30 \mathrm{~h}$ with the indicated drugs, detached by treatment with trypsin-EDTA (Biochrom) and stained with trypan blue solution (Thermo Fisher Scientific). Afterwards a representative amount of 100 cells per well were counted using a Neubauer counting chamber. The stained and unstained cells were evaluated to obtain the percentage of trypan blue positive cells.

Statistics. The graphs and statistics were performed with GraphPad Prism 6 (version 6.05 for Windows, GraphPad Software, La Jolla, CA, USA). The results are presented as line plots with mean and standard deviation or as box plots indicating the median, the $25^{\text {th }}$ and $75^{\text {th }}$ percentile in the form of a box with the $5^{\text {th }}$ and $95^{\text {th }}$ percentiles as whiskers. Differences between the groups were evaluated by the two-tailed Mann-Whitney rank-sum test, followed by Bonferroni correction. Thus, differences with $p \leq 0.05$ divided by the number of meaningful comparisons were considered to be significant while differences with $p \leq 0.08$ divided by the number of meaningful comparisons were considered to show a tendency.

\section{Results}

Galloflavin inhibits lactate production. At first, the lactate metabolism of 6606PDA cells was characterized by treating these cells with distinct concentrations of glucose and oxygen. The lactate concentration was significantly increased in high glucose medium when compared to low glucose medium both in the cell lysate and the cell supernatant (data not shown). A significantly higher lactate concentration under hypoxic conditions was also observed in the cell supernatant, but was not detected in the cell lysate, when compared to normoxic conditions (data not shown). This suggests that lactate production of 6606PDA cells is induced by glucose and hypoxia. The inhibition of lactate production by galloflavin depends on the dosage (Figure 1A) and is significant at a dosage of $80 \mu \mathrm{M}$ when compared to the vehicle treatment (Figure 1B). A similar dosage-dependent decrease of the lactate concentration caused by galloflavin was observed in the cell supernatant (Figure 1C) and is significant at a galloflavin concentration of $80 \mu \mathrm{M}$ compared to vehicle treatment (Figure 1D). The proportional decrease of the intracellular and extracellular lactate concentrations after galloflavin treatment suggests that galloflavin doesn't interfere with the cellular efflux of lactate but impacts the production of lactate by inhibition of lactate dehydrogenase.

Galloflavin and metformin inhibit proliferation. A dosedependent decrease in proliferation was observed when treating 6606PDA cells with galloflavin (Figure 2A). Adding $20 \mathrm{mM}$ metformin caused additional inhibition of proliferation (Figure 2A). Treatment with $20 \mathrm{mM}$ metformin slightly reduced proliferation, whereas $80 \mu \mathrm{M}$ of galloflavin caused significant inhibition of proliferation when compared to vehicle treated control cells (Figure 2B). The combination therapy of $80 \mu \mathrm{M}$ of galloflavin plus $20 \mathrm{mM}$ of metformin also caused a slight decrease in proliferation when compared to galloflavin treated cells and a significant decrease in proliferation when compared to metformin treated cells (Figure 2B). A similar dose dependence in inhibiting cell proliferation is observed when treating MIA PaCa- 2 cells with galloflavin (Figure 2C). At the concentration of 5 and $20 \mu \mathrm{M}$ of galloflavin the addition of $20 \mathrm{mM}$ metformin caused a significantly increased inhibition of proliferation (Figure 2C). In this cell line, the combination of $20 \mu \mathrm{M}$ galloflavin plus $20 \mathrm{mM}$ metformin reduced proliferation significantly when compared to vehicle treated or galloflavin treated cells (Figure 2D). These data suggest that galloflavin and metformin have an additive effect in inhibiting proliferation of pancreatic cancer cells.

Galloflavin and metformin induce cell death. In 6606PDA cells, galloflavin induced cell death in a dose-dependent manner in the absence and presence of metformin (Figure $3 \mathrm{~A})$. At the concentrations of 5 and $20 \mu \mathrm{M}$ galloflavin the addition of $20 \mathrm{mM}$ metformin caused a significantly increased induction of cell death (Figure 3A). Treatment with $20 \mathrm{mM}$ of metformin or $80 \mu \mathrm{M}$ galloflavin induced 
A
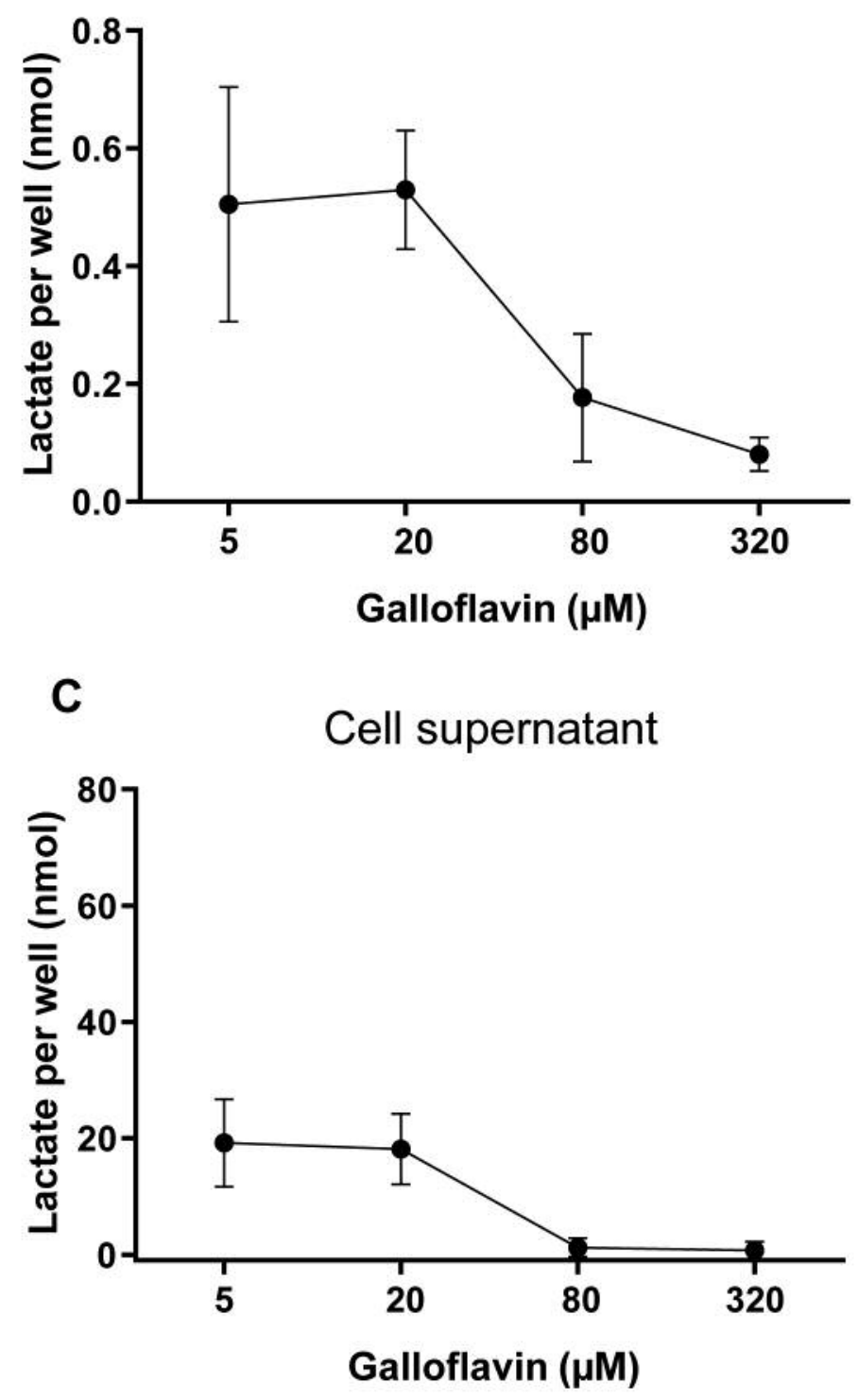

B Cell lysate

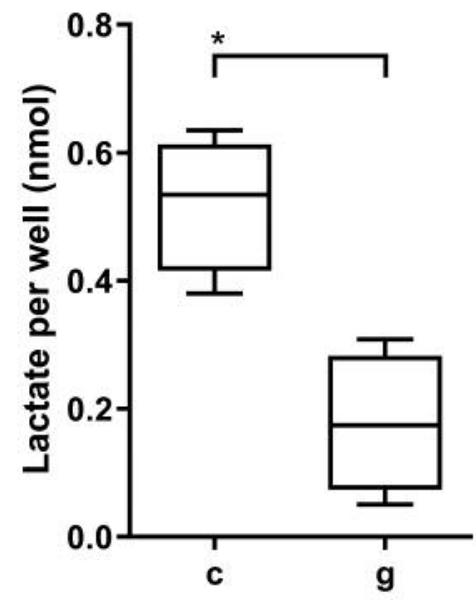

D Cell supernatant

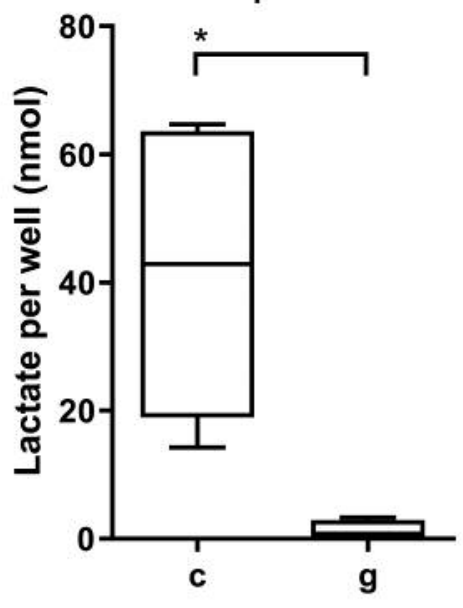

Figure 1. Inhibition of lactate metabolism in 6606PDA cells. (A) Galloflavin reduces lactate concentration in a dosage-dependent manner in the cell lysate. (B) $80 \mu \mathrm{M}$ galloflavin ( $\mathrm{g}$ ) leads to a significant reduction of lactate concentration when compared to vehicle treated cells (c) used as control. $(C)$ A similar dosage dependence and $(D)$ significant reduction of lactate concentration was observed when analyzing the cell supernatant. Significant differences: $* p \leq 0.029(B), * p \leq 0.004(D) ; n=4(A), n=4(B), n=4(C), n(c)=8$ and $n(g)=4(D)$.

significant cell death, when compared to control treated cells (Figure 3B). The combination of metformin plus galloflavin induced slightly more cell death than galloflavin and significantly more cell death than metformin monotherapy (Figure 3B). In MIA PaCa-2 cells, galloflavin also induced cell death in a dose-dependent manner in the absence or presence of metformin (Figure 3C). However, adding metformin did not significantly increase galloflavin-induced cell death (Figure 3C and D). These findings suggest, that only in some cell lines an additive effect on cell death can be observed when treating pancreatic cancer cell lines with metformin plus galloflavin.

Galloflavin and metformin inhibit proliferation under normoxic and hypoxic conditions. In order to evaluate if hypoxia influences the efficacy of galloflavin and 

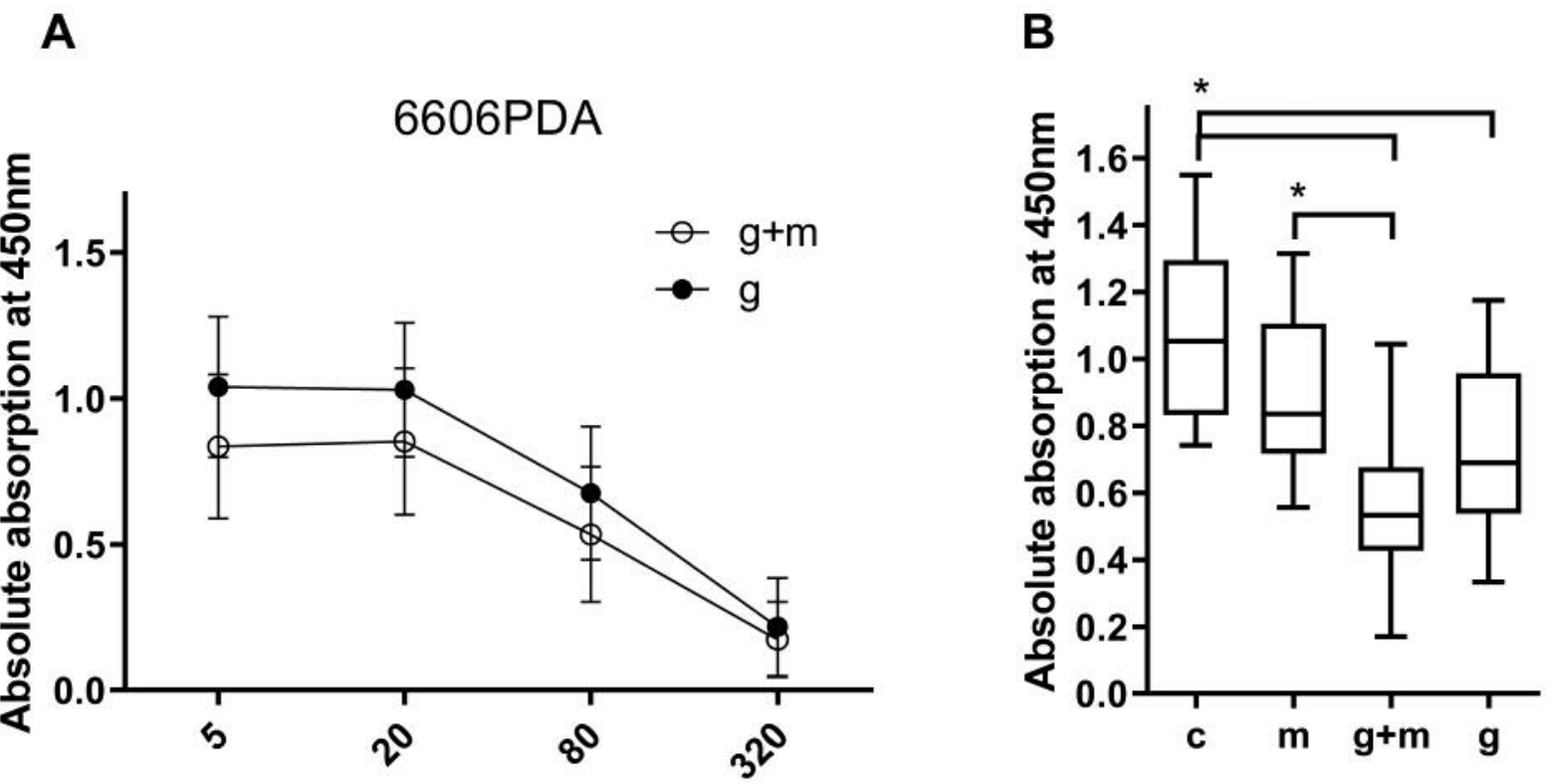

\section{Galloflavin $(\mu \mathrm{M})$}

C
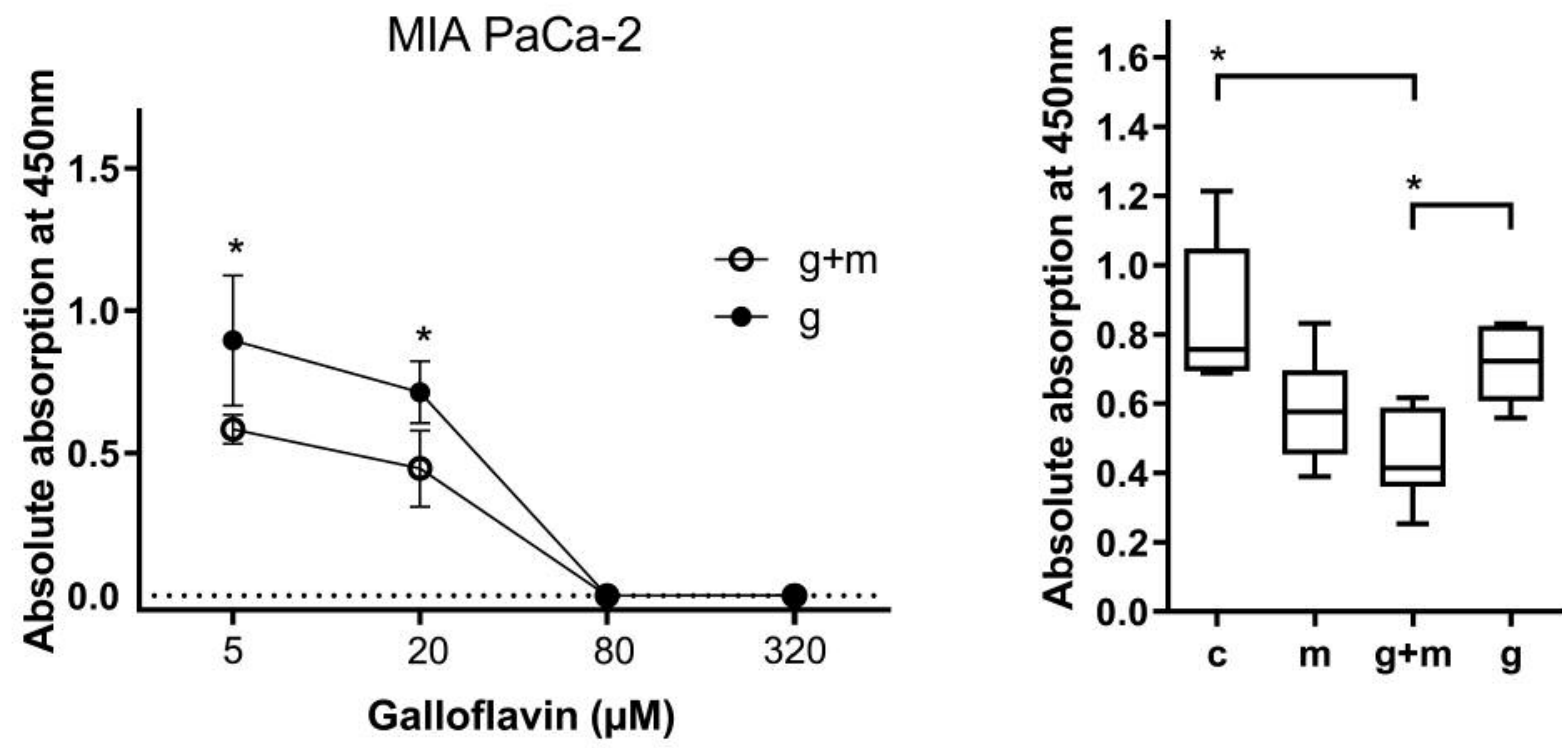

Figure 2. Metformin and galloflavin inhibit the proliferation of pancreatic cancer cells. (A) Galloflavin ( $g$ ) and metformin plus galloflavin ( $g+m)$ reduce the proliferation of 6606PDA cells in a dosage-dependent manner. (B) Compared to vehicle treated cells (c) the proliferation of 6606PDA cells is slightly reduced by metformin $(\mathrm{m})$ and significantly reduced by $80 \mu \mathrm{M}$ galloflavin $(\mathrm{g})$ and the combination of galloflavin plus metformin. (C) A similar dosage dependence is observed in MIA PaCa-2 cells. (D) Compared to vehicle treated cells (c) the proliferation of MIA PaCa-2 cells is slightly reduced by metformin $(\mathrm{m})$ and significantly reduced by $20 \mu \mathrm{M}$ galloflavin $(\mathrm{g})$ and the combination of galloflavin plus metformin. Significant differences: * ${ }^{*} \leq 0.005(B) ; * p \leq 0.004(C) ;{ }^{*} p \leq 0.009(D) ; n=10(A), n=12(B), n=6(C), n=6(D)$.

metformin, the cells were treated with these drugs for $30 \mathrm{~h}$ under normoxic or hypoxic conditions. Under both conditions, $20 \mu \mathrm{M}$ galloflavin only slightly inhibited proliferation, whereas metformin monotherapy caused a significant inhibition of proliferation (Figure 4A and B). The galloflavin plus metformin combination therapy 

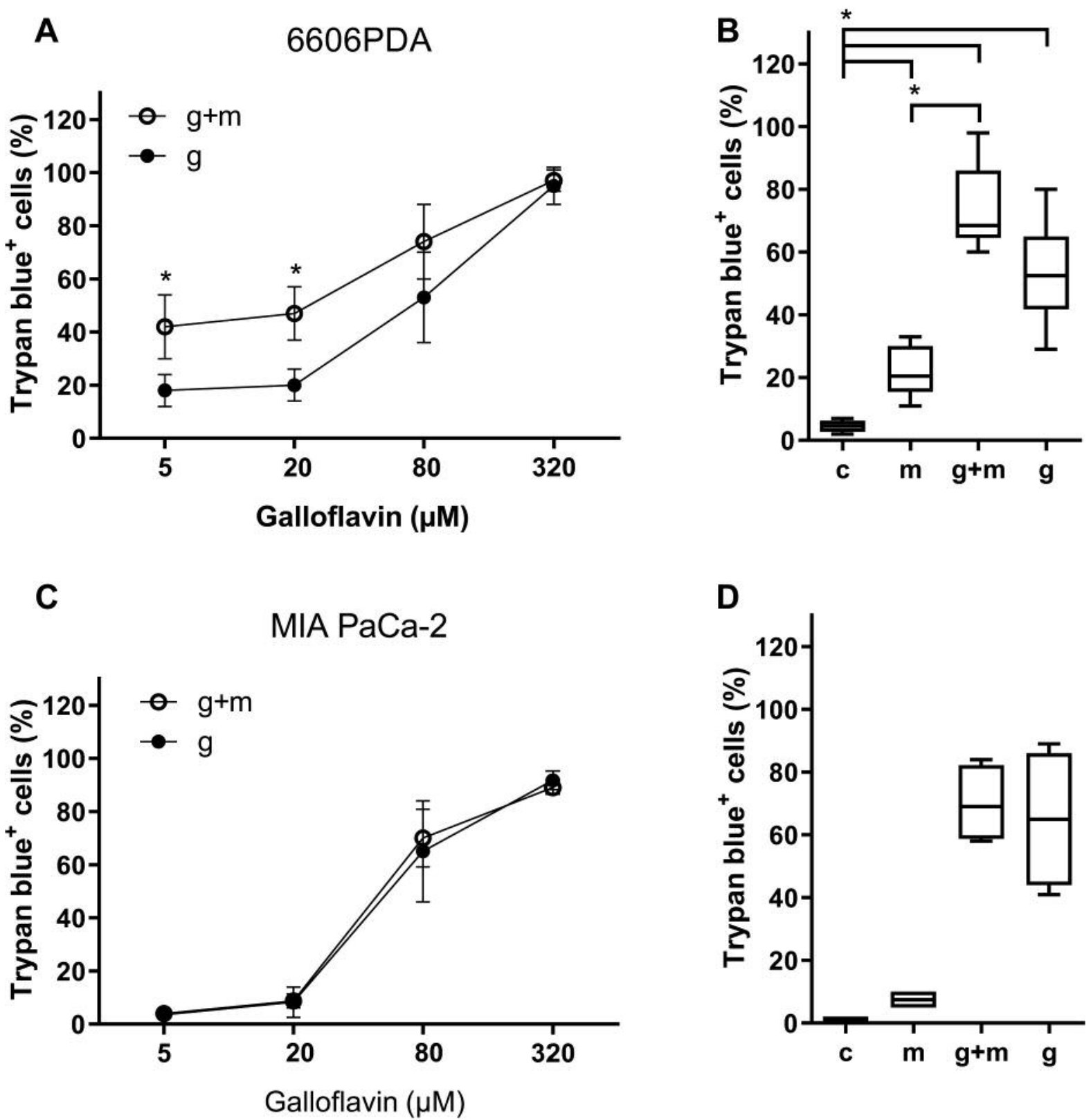

Figure 3. Metformin and galloflavin induce cell death in pancreatic cancer cells. (A) Galloflavin ( $g$ ) and metformin plus galloflavin ( $g+m)$ induce cell death of 6606PDA cells in a dosage-dependent manner. (B) Compared to vehicle treated cells (c) cell death of 6606PDA cells is significantly increased by metformin $(\mathrm{m}), 80 \mu \mathrm{M}$ galloflavin $(\mathrm{g})$ and the combination of galloflavin plus metformin. $(\mathrm{C})$ A similar dosage dependence is observed in MIA PaCa-2 cells. (D) Compared to vehicle treated cells (c) the cell death of MIA PaCa-2 cells is induced by metformin ( $\mathrm{m}), 80 \mu \mathrm{M}$ galloflavin $(\mathrm{g})$, and the combination of galloflavin plus metformin. Significant differences: $* p \leq 0.009(A),{ }^{*} p \leq 0.030(B) ; n=6(A), n=6(B), n=4(C), n=4(D)$.

significantly inhibited proliferation when compared to the monotherapies (Figure 4A and B). This suggests that a combination treatment with galloflavin and metformin could inhibit proliferation in $e . g$. hypoxic large solid tumors as well as in normoxic smaller clusters of cancer cells, e.g. after metastatic dissemination.

\section{Discussion}

In this study we confirmed that galloflavin inhibits lactate production. We found that there is an additive effect of metformin and galloflavin on the inhibition of proliferation and the induction of cell death in pancreatic cancer cells. 
A

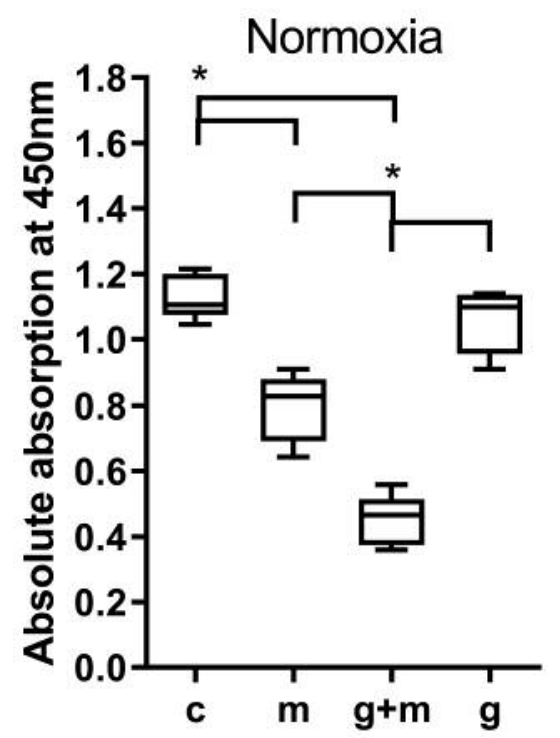

B

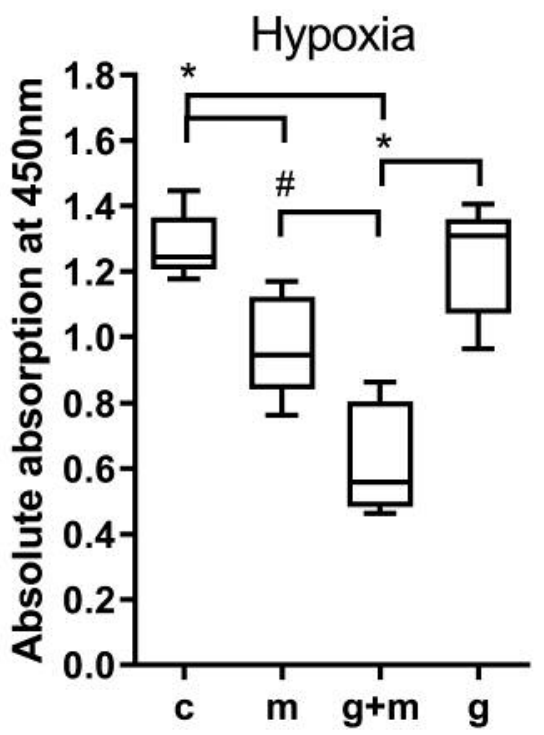

Figure 4. Metformin and galloflavin inhibit the proliferation of pancreatic cancer cells under normoxic and hypoxic conditions. Compared to vehicle treated cells $(c)$ the proliferation of 6606PDA cells is slightly reduced by $20 \mu \mathrm{M}$ galloflavin $(\mathrm{g})$ and significantly reduced by $20 \mathrm{mM}$ metformin $(\mathrm{m})$ and the combination of galloflavin plus metformin $(g+m)$ under $(A)$ normoxic and $(B)$ hypoxic conditions. Significant differences: $* p \leq 0.008(A)$, ${ }^{*} p \leq 0.008$ (B); tendentious difference: ${ }^{*} p \leq 0.016(B), n=5(A), n=5(B)$.

Furthermore, we observed that the inhibition of proliferation by this combinational therapy can be detected under hypoxic and normoxic conditions, leading to the assumption that this combinational therapy could impair insufficiently supplied solid tumors as well as small normoxic clusters of cancer cells, e.g. after metastatic dissemination.

The anti-cancerous effect of metformin, as demonstrated in this study, is consistent with numerous previous publications, which also indicate that metformin monotherapy inhibits pancreatic cancer cell proliferation and induces apoptosis (1517). Galloflavin has, to our knowledge, not been tested in pancreatic cancer cells. The observed anti-cancerous effects of galloflavin are, however, consistent with observations demonstrating that galloflavin impairs cell expansion of various cell lines (18-21). The presented data also demonstrate that the combination of galloflavin and metformin has an additive anti-cancerous effect, which suggests that inhibition of LDH and oxidative phosphorylation might be a useful strategy to treat cancer.

However, it is still controversial which drugs might be best for such a combination therapy. For example, there are promising studies demonstrating that other LDH inhibitors such as N-hydroxyindole-2-carboxylates and FX11 can impair cancer cell proliferation $(22,23)$.

Furthermore, one study by Miskimins et al. suggests that the combination of phenformin, a biguanide inhibiting oxidative phosphorylation, and the LDH inhibitor oxamate synergistically induces cancer cell death in breast, lung, melanoma, colon, prostate and tonsil cancer cells (24). At first glance, phenformin seems to be a more appropriate drug than metformin, because it has a higher efficacy in inhibiting oxidative phosphorylation $(24,25)$. Yet, it has also a higher risk of inducing lactate acidosis $(26,27)$, whereas metformin is known for its safer use in patients $(27,28)$. Other alternatives for metformin could be the highly potent and selective inhibitor of oxidative phosphorylation, called IACS-010759 (29). Oxamate, since it inhibits $\mathrm{LDH}$, can in principle be used in combination with metformin or other inhibitors of oxidative phosphorylation. However, oxamate is a very old drug, which is hydrophilic and is known to penetrate the cytoplasmic membrane poorly, suggesting that it is a good LDH inhibitor for biochemical studies using protein extract, but a poor inhibitor when using entire cells $(30,31)$. Oxamate has also an about 500-fold higher IC50 than galloflavin when applied to whole cells (31). Thus, there are some aspects suggesting that galloflavin is superior to oxamate and that metformin has advantages over phenformin. In conclusion, this study suggests that a galloflavin metformin combination therapy should be tested in preclinical studies for treating pancreatic cancer.

\section{Funding}

The study was supported by B. BRAUN-STIFTUNG (grant number: BBST-D-15-00003). 


\section{Conflicts of Interest}

The Authors declare no conflicts of interest regarding this study.

\section{Authors' Contributions}

Study concepts: DZ, BV; Study design: DZ, BV; Data acquisition: EHUW, MS; Quality control of data and algorithms: EHUW, MS, DZ; Data analysis and interpretation: EHUW, MS, DZ; Statistical analysis: EHUW, MS, DZ; Manuscript preparation: EHUW, DZ; Manuscript editing and review: all Authors.

\section{Acknowledgements}

The Authors would like to thank Prof. Barbara Nebe for providing the hypoxic incubator (Center for Medical Research, Dept. of Cell Biology) and Berit Blendow (Institute for Experimental Surgery, University of Rostock) for excellent technical assistance.

\section{References}

1 Siegel RL, Miller KD and Jemal A: Cancer statistics, 2019. CA Cancer J Clin 69(1): 7-34, 2019. PMID: 30620402. DOI: $10.3322 /$ caac. 21551

2 Li D, Yeung SC, Hassan MM, Konopleva M and Abbruzzese JL: Antidiabetic therapies affect risk of pancreatic cancer. Gastroenterology 137(2): 482-488, 2009. PMID: 19375425. DOI: $10.1053 /$ j.gastro.2009.04.013

3 Wang Z, Lai ST, Xie L, Zhao JD, Ma NY, Zhu J, Ren ZG and Jiang GL: Metformin is associated with reduced risk of pancreatic cancer in patients with type 2 diabetes mellitus: a systematic review and meta-analysis. Diabetes Res Clin Pract 106(1): 19-26, 2014. PMID: 24837144. DOI: 10.1016/j.diabres.2014.04.007

4 Zhou PT, Li B, Liu FR, Zhang MC, Wang Q, Li YY, Xu C, Liu $\mathrm{YH}$, Yao Y and Li D: Metformin is associated with survival benefit in pancreatic cancer patients with diabetes: a systematic review and meta-analysis. Oncotarget 8(15): 25242-25250, 2017. PMID: 28445955. DOI: 10.18632/oncotarget.15692

5 Li X, Li T, Liu Z, Gou S and Wang C: The effect of metformin on survival of patients with pancreatic cancer: a meta-analysis. Sci Rep 7(1): 5825, 2017. PMID: 28724893. DOI: 10.1038/s41598017-06207-x

6 Choi Y, Kim TY, Oh DY, Lee KH, Han SW, Im SA, Kim TY and Bang YJ: the impact of diabetes mellitus and metformin treatment on survival of patients with advanced pancreatic cancer undergoing chemotherapy. Cancer Res Treat 48(1): 171179, 2016. PMID: 25779362. DOI: 10.4143/crt.2014.292

7 Wei M, Liu Y, Bi Y and Zhang ZJ: Metformin and pancreatic cancer survival: Real effect or immortal time bias? Int J Cancer 145(7): 1822-1828, 2019. PMID: 30848544. DOI: 10.1002/ijc.32254

8 Kordes S, Pollak MN, Zwinderman AH, Mathôt RA, Weterman MJ, Beeker A, Punt CJ, Richel DJ and Wilmink JW: Metformin in patients with advanced pancreatic cancer: a double-blind, randomised, placebo-controlled phase 2 trial. Lancet Oncol 16(7): 839-847, 2015. PMID: 26067687. DOI: 10.1016/S14702045(15)00027-3

9 Foretz M, Guigas B, Bertrand L, Pollak M and Viollet B: Metformin: from mechanisms of action to therapies. Cell Metab 20(6): 953-966, 2014. PMID: 25456737. DOI: 10.1016/j.cmet. 2014.09.018
10 Allison SJ, Knight JR, Granchi C, Rani R, Minutolo F, Milner J and Phillips RM: Identification of LDH-A as a therapeutic target for cancer cell killing via (i) p53/NAD(H)-dependent and (ii) p53-independent pathways. Oncogenesis 3: e102, 2014. PMID: 24819061. DOI: 10.1038/oncsis.2014.16

11 Goldman RD, Kaplan NO and Hall TC: Lactic dehydrogenase in human neoplastic tissues. Cancer Res 24: 389-399, 1964. PMID: 14147812.

12 Rong Y, Wu W, Ni X, Kuang T, Jin D, Wang D and Lou W: Lactate dehydrogenase A is overexpressed in pancreatic cancer and promotes the growth of pancreatic cancer cells. Tumour Biol 34(3): 1523-1530, 2013. PMID: 23404405. DOI: 10.1007/s13277013-0679-1

13 Shi M, Cui J, Du J, Wei D, Jia Z, Zhang J, Zhu Z, Gao Y and Xie K: A novel KLF4/LDHA signaling pathway regulates aerobic glycolysis in and progression of pancreatic cancer. Clin Cancer Res 20(16): 4370-4380, 2014. PMID: 24947925. DOI: 10.1158/1078-0432.CCR-14-0186

14 Ždralević M, Brand A, Di Ianni L, Dettmer K, Reinders J, Singer K, Peter K, Schnell A, Bruss C, Decking SM, Koehl G, FelipeAbrio B, Durivault J, Bayer P, Evangelista M, O’Brien T, Oefner PJ, Renner K, Pouysségur J and Kreutz M: Double genetic disruption of lactate dehydrogenases $\mathrm{A}$ and $\mathrm{B}$ is required to ablate the "Warburg effect" restricting tumor growth to oxidative metabolism. J Biol Chem 293(41): 15947-15961, 2018. PMID: 30158244. DOI: $10.1074 /$ jbc.RA118.004180

15 Bao B, Wang Z, Ali S, Ahmad A, Azmi AS, Sarkar SH, Banerjee S, Kong D, Li Y, Thakur S and Sarkar FH: Metformin inhibits cell proliferation, migration and invasion by attenuating CSC function mediated by deregulating miRNAs in pancreatic cancer cells. Cancer Prev Res (Phila) 5(3): 355-364, 2012. PMID: 22086681. DOI: 10.1158/1940-6207.CAPR-11-0299

16 Kisfalvi K, Eibl G, Sinnett-Smith J and Rozengurt E: Metformin disrupts crosstalk between $G$ protein-coupled receptor and insulin receptor signaling systems and inhibits pancreatic cancer growth. Cancer Res 69(16): 6539-6545, 2009. PMID: 19679549. DOI: $10.1158 / 0008-5472 . C A N-09-0418$

17 Wang LW, Li ZS, Zou DW, Jin ZD, Gao J and Xu GM: Metformin induces apoptosis of pancreatic cancer cells. World J Gastroenterol 14(47): 7192-7198, 2008. PMID: 19084933. DOI: 10.3748/wjg.14.7192

18 Manerba M, Vettraino M, Fiume L, Di Stefano G, Sartini A, Giacomini E, Buonfiglio R, Roberti $\mathrm{M}$ and Recanatini M: Galloflavin (CAS 568-80-9): a novel inhibitor of lactate dehydrogenase. ChemMedChem 7(2): 311-317, 2012. PMID: 22052811. DOI: $10.1002 / \mathrm{cmdc} .201100471$

19 Farabegoli F, Vettraino M, Manerba M, Fiume L, Roberti M and Di Stefano G: Galloflavin, a new lactate dehydrogenase inhibitor, induces the death of human breast cancer cells with different glycolytic attitude by affecting distinct signaling pathways. Eur J Pharm Sci 47(4): 729-738, 2012. PMID: 22954722. DOI: 10.1016/j.ejps.2012.08.012

20 Vettraino M, Manerba M, Govoni M and Di Stefano G: Galloflavin suppresses lactate dehydrogenase activity and causes MYC downregulation in Burkitt lymphoma cells through NAD/NADH-dependent inhibition of sirtuin-1. Anticancer Drugs 24(8): 862-870, 2013. PMID: 23797802. DOI: $10.1097 / C A D .0 b 013 e 328363 a e 50$

21 Han X, Sheng X, Jones HM, Jackson AL, Kilgore J, Stine JE, Schointuch MN, Zhou C and Bae-Jump VL: Evaluation of the 
anti-tumor effects of lactate dehydrogenase inhibitor galloflavin in endometrial cancer cells. J Hematol Oncol 8: 2, 2015. PMID: 25631326. DOI: 10.1186/s13045-014-0097-x

22 Granchi C, Roy S, De Simone A, Salvetti I, Tuccinardi T, Martinelli A, Macchia M, Lanza M, Betti L, Giannaccini G, Lucacchini A, Giovannetti E, Sciarrillo R, Peters GJ and Minutolo F: N-Hydroxyindole-based inhibitors of lactate dehydrogenase against cancer cell proliferation. Eur J Med Chem 46(11): 53985407, 2011. PMID: 21944286. DOI: 10.1016/j.ejmech.2011.08.046

23 Le A, Cooper CR, Gouw AM, Dinavahi R, Maitra A, Deck LM, Royer RE, Vander Jagt DL, Semenza GL and Dang CV: Inhibition of lactate dehydrogenase A induces oxidative stress and inhibits tumor progression. Proc Natl Acad Sci USA 107(5): 2037-2042, 2010. PMID: 20133848. DOI: 10.1073/pnas.0914433107

24 Miskimins WK, Ahn HJ, Kim JY, Ryu S, Jung YS and Choi JY: Synergistic anti-cancer effect of phenformin and oxamate. PLoS One 9(1): e85576, 2014. PMID: 24465604. DOI: 10.1371/ journal.pone. 0085576

25 Lea MA, Guzman Y, Desbordes C: Inhibition of growth by combined treatment with inhibitors of lactate dehydrogenase and either phenformin or inhibitors of 6-phosphofructo-2-kinase/ fructose-2,6-bisphosphatase 3. Anticancer Res 36(4): 1479-1488, 2016. PMID: 27069123.

26 McGuinness ME and Talbert RL: Phenformin-induced lactic acidosis: a forgotten adverse drug reaction. Ann Pharmacother 27(10): 1183-1187, 1993. PMID: 8251683.

27 Bando K, Ochiai S, Kunimatsu T, Deguchi J, Kimura J, Funabashi $\mathrm{H}$ and Seki T: Comparison of potential risks of lactic acidosis induction by biguanides in rats. Regul Toxicol Pharmacol 58(1): 155-160, 2010. PMID: 20488215. DOI: 10.1016/j.yrtph.2010.05.005

28 Aharaz A, Pottegård A, Henriksen DP, Hallas J, Beck-Nielsen H and Lassen AT: Risk of lactic acidosis in type 2 diabetes patients using metformin: A case control study. PLoS One 13(5): e0196122, 2018. PMID: 29738540. DOI: 10.1371/journal.pone. 0196122
29 Molina JR, Sun Y, Protopopova M, Gera S, Bandi M, Bristow C, McAfoos T, Morlacchi P, Ackroyd J, Agip AA, Al-Atrash G, Asara J, Bardenhagen J, Carrillo CC, Carroll C, Chang E, Ciurea S, Cross JB, Czako B, Deem A, Daver N, de Groot JF, Dong JW, Feng N, Gao G, Gay J, Do MG, Greer J, Giuliani V, Han J, Han L, Henry VK, Hirst J, Huang S, Jiang Y, Kang Z, Khor T, Konoplev S, Lin YH, Liu G, Lodi A, Lofton T, Ma H, Mahendra M, Matre P, Mullinax R, Peoples M, Petrocchi A, RodriguezCanale J, Serreli R, Shi T, Smith M, Tabe Y, Theroff J, Tiziani S, Xu Q, Zhang Q, Muller F, DePinho RA, Toniatti C, Draetta GF, Heffernan TP, Konopleva M, Jones P, Di Francesco ME and Marszalek JR: An inhibitor of oxidative phosphorylation exploits cancer vulnerability. Nat Med 24(7): 1036-1046, 2018. PMID: 29892070. DOI: 10.1038/s41591-018-0052-4

30 Granchi C and Minutolo F: Anticancer agents that counteract tumor glycolysis. ChemMedChem 7(8): 1318-1350, 2012. PMID: 22684868. DOI: 10.1002/cmdc.201200176

31 Manerba M, Di Ianni L, Fiume L, Roberti M, Recanatini M and Di Stefano G: Lactate dehydrogenase inhibitors sensitize lymphoma cells to cisplatin without enhancing the drug effects on immortalized normal lymphocytes. Eur J Pharm Sci 74: 95102, 2015. PMID: 25930121. DOI: 10.1016/j.ejps.2015.04.022

Received November 18, 2019

Revised November 25, 2019

Accepted November 28, 2019 